\title{
Initial combination therapy of macitentan and tadalafil in pulmonary arterial hypertension
}

\author{
To the Editor:
}

Initial combination therapy plays a central role in managing pulmonary arterial hypertension (PAH) [14]. Patients with low- or intermediate-risk of 1-year mortality at diagnosis should be treated with initial combination therapy with an endothelin receptor antagonist (ERA) and phosphodiesterase type-5 inhibitor (PDE5i) [2-4]. Benefits of initial therapy with the ERA ambrisentan and PDE5i tadalafil were demonstrated in AMBITION [1]; prospective evidence for other treatment combinations within these drug classes is needed.

In SERAPHIN, macitentan, a dual ERA, improved long-term outcomes in PAH patients [5], including those receiving background treatment (predominantly PDE5i) [5, 6]. OPTIMA (NCT02968901) was a prospective, multicentre, single-arm, open-label, phase IV study that explored the efficacy and safety of macitentan administered as initial oral combination therapy with tadalafil, in newly diagnosed, treatment-naïve $\mathrm{PAH}$ patients.

Treatment-naïve adult patients diagnosed with PAH within the previous 6 months were eligible if they had idiopathic, heritable or associated PAH (drug/toxin-induced, connective tissue disease (CTD), HIV, corrected congenital heart disease). Patients were World Health Organization functional class (FC) II to III, with 6-min walk distance $(6 \mathrm{MWD}) \geqslant 50 \mathrm{~m}$ and the following haemodynamics at screening: resting mean pulmonary arterial pressure $(\mathrm{mPAP}) \geqslant 25 \mathrm{mmHg}$, pulmonary arterial wedge pressure (PAWP) or left ventricular end diastolic pressure $\leqslant 15 \mathrm{mmHg}$, and pulmonary vascular resistance (PVR) $\geqslant 5$ Wood units if PAWP was $<12 \mathrm{mmHg}$, or PVR $\geqslant 6.25$ Wood units if PAWP was $12-15 \mathrm{mmHg}$. Written informed consent was obtained from all patients and the study conducted in accordance with the Declaration of Helsinki and Good Clinical Practice.

The study included a 16-week period during which efficacy and safety were assessed followed by an optional extension period assessing safety. Within 28 days of screening, macitentan $10 \mathrm{mg}$ once daily and tadalafil $20 \mathrm{mg}$ once daily were initiated; at day $8 \pm 3$, the tadalafil dose was increased to $40 \mathrm{mg}$ once daily. The dose of tadalafil could be decreased for tolerability reasons. Study treatment continued until week 16, or until PAH progression required administration of other PAH drugs. Patients who completed 16 weeks of treatment could enter an extension period with macitentan, tadalafil or both drugs until the sponsor stopped the trial, or patient/investigator decision to discontinue both treatments. Patients who discontinued both treatments had an end-of-treatment safety visit within 7 days. All patients had an end-of-study safety visit 30 days after the end of treatment.

Clinical assessments and right heart catheterisation (RHC) were performed at baseline and at week 16. Safety laboratory testing was performed monthly during the first 6 months, after which it was recommended monthly and performed at the discretion of the treating physician. Adverse events were monitored until 30 days after the end of treatment. The primary end-point was the ratio of week 16 to baseline PVR assessed by RHC. Secondary end-points were: percentage of patients with PVR decrease $\geqslant 30 \%$ from baseline to week 16; change from baseline to week 16 in mean right atrial pressure, mPAP, cardiac index, total pulmonary resistance, mixed venous oxygen saturation, $6 \mathrm{MWD}, \mathrm{FC}$ and $\mathrm{N}$-terminal pro-brain natriuretic peptide (NT-proBNP); and percentage of patients with improvement/worsening FC from baseline to week 16. A pre-specified exploratory end-point was the number of low-risk criteria at

@ERSpublications

Initial combination therapy with macitentan and tadalafil is well tolerated and improves cardiopulmonary haemodynamics and functional capacity in newly diagnosed PAH patients https://bit. ly/3aWZagH

Cite this article as: Sitbon $\mathrm{O}$, Cottin V, Canuet $\mathrm{M}$, et al. Initial combination therapy of macitentan and tadalafil in pulmonary arterial hypertension. Eur Respir J 2020; 56: 2000673 [https://doi.org/10.1183/ 13993003.00673-2020]. 
TABLE 1 Haemodynamic parameters, 6-min walk distance (6MWD), N-terminal pro-brain natriuretic peptide (NT-proBNP) concentrations, World Health Organization functional class (FC) and low-risk criteria

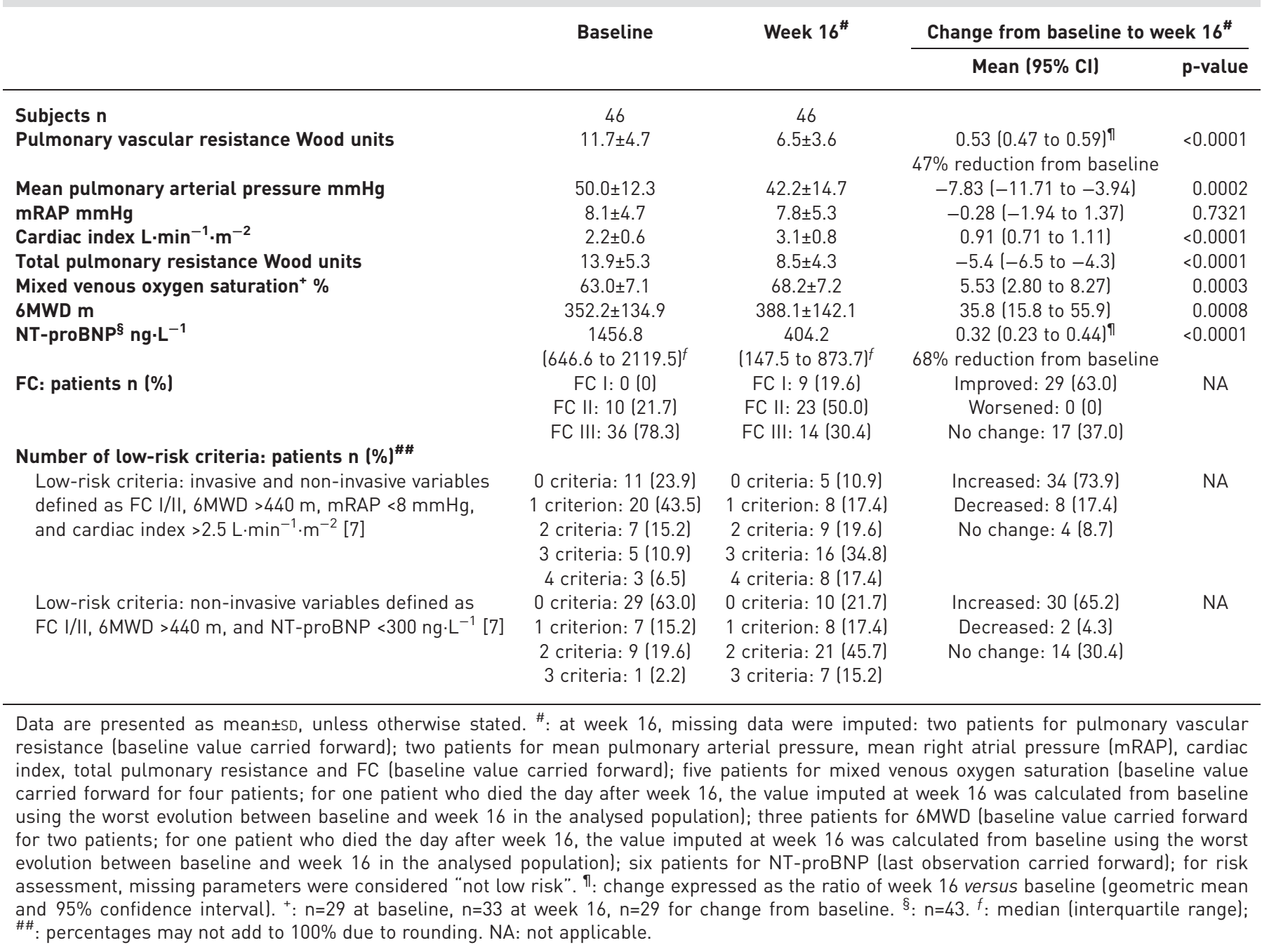

baseline and week 16. Two sets of parameters were assessed and the thresholds used to define low-risk were updated post hoc to align with those recommended in the European Society of Cardiology (ESC)/ European Respiratory Society (ERS) guidelines [2,3] and validated in a French registry analysis [7]. For PVR and NT-proBNP, ratios of week 16 versus baseline were log-transformed and the geometric mean of the ratio and its $95 \%$ two-sided confidence interval obtained by exponentiation. Other parameters were summarised descriptively.

From November 2015 to December 2017, 50 patients were screened at 15 sites in France. 46 patients were enrolled and 44 completed 16 weeks of treatment (two discontinued both drugs due to: aetiology revision, $\mathrm{n}=1$; adverse event and suspicion of veno-occlusive disease, $\mathrm{n}=1) .44$ patients entered the extension period and 39 completed the study (five discontinued both drugs due to: adverse event and aetiology revision, $\mathrm{n}=1$; adverse event and death, $\mathrm{n}=1$; death, $\mathrm{n}=2$; patient decision, $\mathrm{n}=1)$. Patients were predominantly female $(65.2 \%)$ with idiopathic $(63.0 \%)$ or CTD-associated (19.6\%) PAH, and were FC II (21.7\%) or III (78.3\%), with a mean \pm SD 6 MWD of $352.2 \pm 134.9 \mathrm{~m}$. Mean \pm SD age was $57.4 \pm 14.9$ years and time from PAH diagnosis was $29.6 \pm 55.2$ days $(n=45)$. All patients were titrated to tadalafil $40 \mathrm{mg}$ once daily, the majority within $8 \pm 3$ days. Tadalafil dose reductions to $20 \mathrm{mg}$ once daily occurred in two patients, both between day 15 and week 16 .

The geometric mean ratio of week 16 to baseline PVR was 0.53 (95\% CI 0.47-0.59), representing a $47 \%$ reduction (table 1). A $\geqslant 30 \%$ decrease in PVR between baseline and week 16 occurred in $87.0 \%$ (95\% CI 73.7-95.1) of patients. Changes in other haemodynamic parameters, 6MWD, NT-proBNP concentration, FC, and the number of low-risk criteria are shown in table 1. 
Median (interquartile range) exposure to macitentan and tadalafil was 86.5 (53.0-115.1) weeks. At least one adverse event was reported in $43(93.5 \%)$ patients and serious adverse events were reported in $13(28.3 \%)$ patients. Three $(6.5 \%)$ patients had an adverse event leading to study treatment discontinuation (both study drugs) (one adverse event of lack of efficacy before week 16, one of treatment inefficiency after week 16, and one of PAH worsening after week 16). Most frequent adverse events were peripheral oedema (28.3\%), headache (23.9\%), diarrhoea (19.6\%), dyspnoea (15.2\%), anaemia (13.0\%) and asthenia (13.0\%). Haemoglobin decreases to $>8$ and $\leqslant 10 \mathrm{~g} \cdot \mathrm{dL}^{-1}$ were reported for five $(10.9 \%)$ patients (who had baseline values ranging from 10.9 to $\left.13.4 \mathrm{~g} \cdot \mathrm{dL}^{-1}\right)$, with no decreases to $\leqslant 8 \mathrm{~g} \cdot \mathrm{dL}^{-1}$. No patients discontinued study treatment due to decreased haemoglobin. Aspartate aminotransferase levels above three times the upper limit of normal (ULN) without bilirubin elevation above double the ULN were reported in one patient but did not lead to treatment discontinuation. Three patients died (one due to multiorgan failure on day 764 and two due to underlying disease, on days 127 and 588). Kaplan-Meier survival estimates were 97.7\% (95\% CI 84.9\%-99.7\%) at 12 months, $93.7 \%$ (95\% CI $75.7 \%-98.5 \%)$ at 24 months and $87.8 \%(95 \%$ CI $64.5 \%-96.2 \%)$ at end of study (2.7 years).

Our findings are aligned with those from previous randomised controlled trials and real-world studies where haemodynamic and functional improvement was observed following initial ERA and PDE5i combination therapy $[1,8-12]$. Safety and tolerability were generally consistent with previous data for macitentan in combination with PDE5i $[5,6,13]$. The main limitations of our study were the open-label uncontrolled nature of the design and the small sample size.

Overall, in the prospective OPTIMA study, initial double combination therapy with macitentan and tadalafil led to a significant improvement, from baseline to week 16, in cardiopulmonary haemodynamics, functional parameters, NT-proBNP and risk profile in newly diagnosed, treatment-naïve patients with PAH. There were no unexpected safety findings during long-term follow-up. In line with recommendations in the ESC/ERS guidelines $[2,3]$ and proceedings from the 6th World Symposium on Pulmonary Hypertension [4], the data presented here support early use of double oral combination therapy with an ERA and PDE5i to optimally manage PAH.

Olivier Sitbon $\odot^{1}$, Vincent Cottin $\oplus^{2}$, Matthieu Canuet $\oplus^{3}$, Pierre Clerson ${ }^{4}$, Virginie Gressin ${ }^{5}$, Loïc Perchenet ${ }^{5}$, Laurent Bertoletti $\oplus^{6,7}$, Hélène Bouvaist ${ }^{8}$, François Picard ${ }^{9}$, Grégoire Prévot $^{10}$, Emmanuel Bergot ${ }^{11}$ and Gérald Simonneau ${ }^{1}$

${ }^{1}$ APHP, National Reference Centre for Pulmonary Hypertension, Dept of Respiratory and Intensive Care Medicine, Bicêtre Hospital, University Paris-Sud - University Paris Saclay, INSERM UMR_S999, Le Kremlin-Bicêtre, France. ${ }^{2}$ National Reference Centre for Rare Pulmonary Diseases, Dept of Pneumology, Louis Pradel Hospital, Claude Bernard University Lyon 1, UMR754, Lyon, France. ${ }^{3}$ Dept of Pneumology, Nouvel Hôpital Civil, Strasbourg, France. ${ }^{4}$ Soladis Clinical Studies, Biostatistics, Roubaix, France. ${ }^{5}$ Actelion Pharmaceuticals Ltd, Allschwil, Switzerland. ${ }^{6}$ Dept of Vascular Medicine and Therapeutics, Saint-Étienne University Hospital Centre, Saint-Étienne, France. ${ }^{7}$ INSERM (National Institute of Health and Medical Research) U1059 and INSERM CIC1408, Saint-Étienne, France. ${ }^{8}$ Cardiology Service, Michallon Hospital, Grenoble University Hospital Centre, Grenoble, France. ${ }^{9}$ Heart Failure Unit and Pulmonary Hypertension Expert Centre, Bordeaux University Hospital, Bordeaux, France. ${ }^{10}$ Dept of Pneumology, University Hospital, Toulouse, France. ${ }^{11}$ Dept of Pneumology, University Hospital, Caen, France.

Correspondence: Olivier Sitbon, Service de Pneumologie, CHU Bicêtre, 78 rue du Général Leclerc, 94275 Le KremlinBicêtre, France. E-mail: olivier.sitbon@u-psud.fr

Received: 30 Sept 2019 | Accepted after revision: 4 April 2020

Acknowledgements: The authors would like to thank the patients and the investigators for their contribution to the study. Medical writing assistance was provided by Laura Corbett (nspm ltd, Meggen, Switzerland) and funded by Actelion Pharmaceuticals Ltd (Allschwil, Switzerland).

Conflict of interest: O. Sitbon reports personal fees from Actelion Pharmaceuticals France Ltd for steering committee work and non-financial editorial support from Actelion Pharmaceuticals Ltd, during the conduct of the study; grants, personal fees for advisory board work, consultancy, steering committee work and lectures, and non-financial editorial support from Actelion Pharmaceuticals Ltd and GlaxoSmithKline, grants and personal fees for advisory board work, consultancy and lectures from Bayer HealthCare and Merck, personal fees for consultancy and advisory board work from Arena Pharmaceuticals, personal fees for advisory board work from Gossamer Bio and Ferrer, outside the submitted work. V. Cottin reports non-financial editorial support from Actelion Pharmaceuticals Ltd, personal fees for steering committee work from Actelion Pharmaceuticals France Ltd, during the conduct of the study; personal fees for advisory board work and lectures, and non-financial travel support from Actelion Pharmaceuticals Ltd, grants, personal fees for consultancy and lectures, and non-financial travel support from Boehringer Ingelheim and Roche, personal fees for advisory board and data monitoring committee work from Bayer/MSD and Galapagos, personal fees for adjudication committee work from Gilead, personal fees for advisory board work and lectures from Novartis, personal fees for lectures from Sanofi, personal fees for data monitoring and steering committee work from Promedior, personal fees for data monitoring committee work from Celgene and Galecto, outside the submitted work. M. Canuet reports non-financial editorial support from Actelion Pharmaceuticals Ltd, personal fees for steering committee work from Actelion Pharmaceuticals France Ltd, during the conduct of the study; personal fees for consultancy from Actelion Pharmaceuticals Ltd, outside the submitted work. P. Clerson reports non-financial editorial support from Actelion Pharmaceuticals Ltd, during the conduct of the study. 
V. Gressin reports non-financial editorial support from Actelion Pharmaceuticals Ltd, was an employee of Actelion Pharmaceuticals France Ltd during the conduct of the study, has RSU in parent company Johnson and Johnson, and owns shares in Idorsia Pharmaceuticals Ltd. L. Perchenet reports non-financial editorial support from Actelion Pharmaceuticals Ltd, during the conduct of the study; and is an employee of Actelion Pharmaceuticals Ltd. L. Bertoletti reports non-financial editorial support from Actelion Pharmaceuticals Ltd, during the conduct of the study; non-financial support for travel and advisory board work from Actelion Pharmaceuticals Ltd, personal fees for advisory board work and non-financial support for travel from Bayer, non-financial support for travel from Pfizer, personal fees for advisory board work from Daichii-Sankyo, outside the submitted work. H. Bouvaist reports non-financial editorial support from Actelion Pharmaceuticals Ltd, during the conduct of the study. F. Picard reports non-financial editorial support from Actelion Pharmaceuticals Ltd, personal fees for steering committee work from Actelion Pharmaceuticals France Ltd, during the conduct of the study; personal fees and non-financial support from Novartis, outside the submitted work. G. Prévot reports non-financial editorial support from Actelion Pharmaceuticals Ltd, personal fees for steering committee work from Actelion Pharmaceuticals France Ltd, during the conduct of the study. E. Bergot reports non-financial editorial support from Actelion Pharmaceuticals Ltd, personal fees for steering committee work from Actelion Pharmaceuticals France Ltd, during the conduct of the study; personal fees for advisory board work and lectures from Chiesi Pharmaceuticals, Actelion Pharmaceuticals Ltd, Boehringer Ingelheim, Roche, Novartis and AstraZeneca, outside the submitted work. G. Simonneau reports non-financial editorial support from Actelion Pharmaceuticals Ltd, personal fees for steering committee work and non-financial travel/accommodation support from Actelion Pharmaceuticals France Ltd, during the conduct of the study; grants, personal fees for consultancy and lectures and non-financial travel/accommodation support from Actelion Pharmaceuticals Ltd, grants, personal fees for consultancy, steering committee work and lectures, and non-financial travel/ accommodation support from Bayer Healthcare, personal fees for consultancy and lectures and non-financial travel/ accommodation support from MSD and Acceleron, outside the submitted work

Support statement: This study was funded by Actelion Pharmaceuticals France. Funding information for this article has been deposited with the Crossref Funder Registry.

\section{References}

1 Galiè N, Barbera JA, Frost AE, et al. Initial use of ambrisentan plus tadalafil in pulmonary arterial hypertension. $N$ Engl J Med 2015; 373: 834-844.

2 Galiè N, Humbert M, Vachiéry JL, et al. 2015 ESC/ERS Guidelines for the diagnosis and treatment of pulmonary hypertension: The Joint Task Force for the Diagnosis and Treatment of Pulmonary Hypertension of the European Society of Cardiology (ESC) and the European Respiratory Society (ERS). Eur Heart J 2016; 37: 67-119.

3 Galiè N, Humbert M, Vachiéry JL, et al. 2015 ESC/ERS Guidelines for the diagnosis and treatment of pulmonary hypertension: The Joint Task Force for the Diagnosis and Treatment of Pulmonary Hypertension of the European Society of Cardiology (ESC) and the European Respiratory Society (ERS). Eur Respir J 2015; 46: 903-975.

4 Galiè N, Channick RN, Frantz RP, et al. Risk stratification and medical therapy of pulmonary arterial hypertension. Eur Respir J 2019; 53: 1801889.

5 Pulido T, Adzerikho I, Channick RN, et al. Macitentan and morbidity and mortality in pulmonary arterial hypertension. N Engl J Med 2013; 369: 809-818.

6 Jansa P, Pulido T. Macitentan in pulmonary arterial hypertension: a focus on combination therapy in the SERAPHIN trial. Am J Cardiovasc Drugs 2018; 18: 1-11.

7 Boucly A, Weatherald J, Savale L, et al. Risk assessment, prognosis and guideline implementation in pulmonary arterial hypertension. Eur Respir J 2017; 50: 1700889.

8 D'Alto M, Romeo E, Argiento P, et al. Initial tadalafil and ambrisentan combination therapy in pulmonary arterial hypertension: cLinical and haemodYnamic long-term efficacy (ITALY study). J Cardiovasc Med 2018; 19: 12-17.

9 van de Veerdonk MC, Huis In T Veld AE, Marcus JT, et al. Upfront combination therapy reduces right ventricular volumes in pulmonary arterial hypertension. Eur Respir J 2017; 49: 1700007.

10 Badagliacca R, Raina A, Ghio S, et al. Influence of various therapeutic strategies on right ventricular morphology, function and hemodynamics in pulmonary arterial hypertension. J Heart Lung Transplant 2018; 37: 365-375.

11 Sitbon O, Sattler C, Bertoletti L, et al. Initial dual oral combination therapy in pulmonary arterial hypertension. Eur Respir J 2016; 47: 1727-1736.

12 Bachetti C, Manes A, Dardi F, et al. Comparison between initial combination therapy and initial monotherapy in pulmonary arterial hypertension: a single centre blinded evaluation of patients enrolled in the AMBITION study. Am J Respir Crit Care Med 2015; 191: A4779.

13 Chin KM, Channick R, Kim NH, et al. OPUS registry: Treatment patterns with macitentan in patients with pulmonary arterial hypertension. Am J Crit Care Med 2017; 195: A2299. 